\title{
Embracing the muddle: learning from the experiences from interdisciplinary teaching and learning collaboration
}

New Zealand Journal of Teachers' Work, Volume 14, Issue 2, 136-154, 2017

\section{CAROL NEILL}

School of Social Sciences and Public Policy

Auckland University of Technology

DEBORAH CORDER

School of Language and Culture

Auckland University of Technology

KERI-ANNE WIKITERA

STEPHEN COX

School of Hospitality and Tourism

Auckland University of Technology

\section{ABSTRACT}

Interdisciplinary, collaborative teaching and learning is recognised as important for twenty-first century tertiary education that seeks to build students' critical thinking, cultural competence and global understanding. The core elements needed for truly successful collaboration are, however, little understood. This article presents a critical case study of a teaching team's reflections on experiences in collaborating over two years to deliver a new interdisciplinary undergraduate course focused on culture and society. The findings highlight the importance of building a robust team culture built upon shared leadership, mutual trust and commitment, grounded by strong institutional support, to give any collaboration integrity and sustainability.

\section{INTRODUCTION}

Tertiary institutions are continuously searching for innovative approaches to teaching and learning to meet the changing demands of students who live in a world of fast-paced social change. Innovation is required not just in relation to course content, but also in the way teaching and learning is facilitated. Increasingly, there is a shift in teaching and learning approaches towards creating contexts that are collaborative and transcend the disciplinary boundaries of teaching staff and students.

At Auckland University of Technology (AUT), collaborative interdisciplinary teaching and learning has been a primary pursuit in the development of a new 
common course for first year undergraduate students in all Bachelor of Arts (BA) programmes in the Faculty of Culture and Society. The authors of this paper were core members in a diverse, multi-disciplinary team established to develop and deliver a new course, entitled 'Culture and Society'. The team was invited to be bold and innovative in designing the course, and started with a 'blank canvas' in all aspects of the curriculum design and in establishing the collaboration. This required challenging the status quo. The team chose from the outset to create a collaborative approach that differed from those its members had experienced in their university teaching roles, or in other teaching teams. The team consciously developed collaboration through the first two years of course delivery by intense processes of discussion, negotiation, and collective reflexivity.

The team members recognised over time that while they were challenged in the new course approach, their students were engaging and producing work that was exciting and special, and that their own professional learning was substantial. When they sought to find ways to explain their approach, however, they found existing collaborative models to be inadequate. They sought to capture their own reflections on experience, to analyse them and articulate what they saw as key elements of the success of their collaboration. This article presents what they found, with the goal of informing similar future collaborative endeavours.

\section{BACKGROUND}

The Culture and Society course was built on a rationale of students developing their knowledge and understanding of important social and cultural issues in the context of rapid global change. The course would work towards 'grounding' students' understanding of their own and others' cultural identities and social positioning, as a foundation for their learning in their respective BA degrees and future professional and citizenship endeavours. The intent was that the teaching would support students to identify and articulate their ontological positions, to reflect on the 'self' and develop identity awareness in the context of social change and the cultural and social dynamics of contemporary society. This would be done with exposure to different disciplinary lenses on these ideas.

In designing the course the team endeavoured to explicitly centre the student in the curriculum, and to break through traditional boundaries of teaching and create innovative learning environments both in the classroom and online. The strategies challenged students to develop their critical thinking skills, social resilience and intercultural competence. It was important for the collaboration to be organised well to ensure support for all of the new elements of their approach, so that there was consistency in course content and good support in place for all of the large, culturally- and disciplinary-diverse student cohort (with 200-300+ students in each semester) comprised of numerous tutorial groups.

Four members of the course design team, from the disciplines of Social Sciences, Languages, and Hospitality and Tourism, became 'core' teaching staff for the course through the first two years (four semesters), with one taking on the role of course 'leader' and taking the main responsibility for coordination and support of the teaching team, logistical arrangements and administrative issues. Other staff from the disciplines of Education and Māori and Indigenous Development joined for one or two semesters within that two-year period, so that there were between six and eight members in each semester. 
The interdisciplinary nature of the course and the new practices in student engagement and assessment that were to be implemented from the start challenged not only the students, but also the teaching staff. The team sought to act inter-culturally, to openly share their different disciplinary perspectives and practices, learn from each other's experiences, and to ensure consistency of teaching and engagement with students regardless of their disciplinary differences. Hence, close collaboration practices were deemed necessary to ensure that the design and delivery of the course evolved appropriately to meet student and teaching staff needs.

Collaboration was organised in practice so that the teaching team members had collective responsibility for the weekly lectures, and individual leadership of respective tutorial streams. The entire teaching team's collective engagement in the lecture sessions was crucial to the collaboration, so that each week the lecture was led by a content specialist on the designated topic, but organised to enable additional input from members of the teaching team and students about their respective disciplinary views and experiences in relation to the subject. The teaching team then met after each lecture to discuss the lecture's content and different ideas that had been brought up in it, and to plan strategies to consolidate the student learning and engagement with the topic in tutorials. The team dialogue was continued each week through follow up communication via group email and an online Google community, where resources for tutorials were shared and members reported back on their tutorial experiences, outlining what had been tried and how well they felt it worked.

Through the first two years of the course delivery and collaboration, the teaching team members regularly conducted collective reflections, particularly as part of the team moderation meetings that were held for each assessment from semester to semester. As the team members considered how well the teaching aims were reflected by the students' work and class engagement, they also sought to assess the effectiveness of teaching innovations, how these affected their students' learning experiences, and what changes would be made to more effectively achieve the course aims.

\section{LITERATURE REVIEW}

Literature that is relevant to this research sits across a range of subject areas, including those focused on interdisciplinary curriculum delivery, collaborative teaching approaches, and professional teaching development. Key ideas from these relevant to this study are outlined below.

\section{Interdisciplinary teaching and learning}

Pursuits to expose tertiary students to interdisciplinary learning contexts reflect broader trends in tertiary teaching towards developing students' social understanding and inter-cultural competence. This fits with writers such as Millar (2016), who emphasises the challenge to modern universities to meet a wider range of stakeholder demands and influences than were traditionally apparent. She notes that in order to support students to be effective future employees, "interdisciplinarity has arisen as one possible part of the solution" (2016, p. 472). Such a view also recognises that knowledge production in contemporary society is not only the domain of higher education institutions, and graduates need to be able to converse and share ideas across disciplinary boundaries with those 
creating and producing innovation in wide ranges of 'real world' situations (Frodeman, 2014).

Teaching and learning contexts need to provide for active student participation in learning that includes theory and practice (Summerlee, 2016, emphasis added), and experiential learning opportunities that lead to deep learning. Being able to apply ideas to the 'real world' and being challenged to identify, accept and understand different perspectives - even those in contrast or conflict to one's own - is noted as important for students to build (Meyer \& Land, 2003). Accordingly, in interdisciplinary contexts there is a need for intentionality in working with students, to help them detect differences (which are often subtle) between disciplines (Bryant, Niewolny, Clark \& Watson, 2014).

Interdisciplinary teaching and learning approaches commonly pursue critical thinking skills development. As Moore (2011, p. 271) points out, however, critical thinking can refer to "a multiplicity of practices, ones that are rooted in the quite individual nature of different disciplinary language (and thinking) games". Equipping students with confidence to "take a critical stance in the world" (Harland \& Pickering, 2011, p. 5) including across disciplinary modes (Moore, 2011), has been argued as important.

Achievement of the objectives of interdisciplinary teaching can lead to transformative learning whereby students are challenged to identify, question and critically think and reflect upon their own deep-seated cultural assumptions or 'frames of reference', and experience conscious shifts in world view (Mezirow, 1997). This process is recognised to often be difficult for students, causing conflicting responses (Colwill \& Boyd, 2008). The ability to cope with the complexity of social and cultural contexts is, however, considered important in the increasingly diverse landscape of contemporary society (Brooks, 2017), and achieving this goal is deemed important if higher education is to be "a site for personal engagement, transformation and change" (Walker, 2005, p. 3).

\section{Collaborative teaching approaches}

The interdisciplinary 'integrated learning experience', while argued as vital for today's students, is nonetheless acknowledged as challenging to develop and deliver successfully. A common primary concern when engaging with multiple perspectives is achieving breadth and depth of learning without compromising either (Conley, 2015). Creating successful, sustainable interdisciplinary teaching teams is also difficult. Different disciplinary perspectives need to not just be included in the curriculum but integrated. Teachers can also become confronted by different teaching approaches and focus points (Bryant et al., 2014; Pharo, Davison, McGregor, Warr \& Brown, 2014). There needs, therefore, to be a willingness present amongst all teaching staff to engage with multiple disciplinary approaches (Newell \& Green, 1982, cited in Bryant et al., 2014); something that is often not easy if their academic training has been very discipline-specific (Frodeman, 2014). Even if not always an explicit condition of successful interdisciplinary teaching and learning contexts (Bryant et al., 2014), collaboration is accepted as important in such circumstances,

Collaboration in teaching and learning contexts can take a range of forms, from a "modular", approach which resembles separate divisions of labour, to "traditional" modes that require integrated, interdependent sharing of teaching across team members and disciplines (Bryant et al., 2014). Some have called the former "serial' team teaching" or "sequenced solo teaching" (Lester \& Evans, 
2009, p. 374), and note them as tending to be more common forms of collaboration because they are usually easier to organise. Communities of practice are recognised as providing a basis for more intensive collaborative approaches, but they tend to be developed through informal, self-organised voluntary connections across institutional boundaries rather than being deliberately instituted. In some cases, however, these have been developed with explicit intentions of working cooperatively towards specific common goals, such as with interdisciplinary teaching teams (Pedersen, 2017; Pharo et al., 2014).

Collaborative teams and communities of practice have been recognised as needing to be held together by trust, tolerance and mutual respect between members (Pharo et al., 2014). This requires strong commitment from members who need to sometimes work beyond the formal scope of their role to maintain those bonds. It has been found that this is often more successful in small group or paired collaborations rather than through a large community membership (Bryant et al., 2014; Pharo et al., 2014). Here the nature of leadership within the community can influence the group's success, because in such contexts traditional hierarchies and ways of doing are often found to be inadequate (Smith \& McKeen, 2003). Bryant et al. (2014) further note the important role that institutional structures and support play in influencing the sustainability of interdisciplinary collaborations.

\section{Inter-cultural teaching and professional learning}

Collaborative and interdisciplinary approaches are noted as needing to accommodate the embedded discipline culture (Wallerstein, 2003), professional teaching identities, and the worldviews of teachers and students. Teaching collaboration across disciplines therefore inevitably necessitates the development of inter-cultural interaction and understanding. Teachers can find themselves feeling professionally and personally challenged and disrupted by interdisciplinary course expectations, while at the same time needing to support students who feel confronted by intercultural learning objectives which might be quite different to their own programme's main focus areas (Bryant et al., 2014).

Cultural and disciplinary identity can provide a source of friction between teachers from different fields given the influence this can have over what is considered important and emphasised in teaching and learning practice (Beijaard, Meijer \& Verloop, 2004). A challenge can be that teachers may not be clear on their own professional identity (Beijaard et al., 2004), or see this as conflicting with that of their colleagues, or the way concepts are usually approached for study. It requires them to take a broader disciplinary 'gaze' than they usually are required to do (Frodemen, 2014), and to be culturally responsive in their practice.

Ironically, discussion on inter-cultural learning tends to assume a Westernised perspective towards the idea of diversity in society. Indigenous thinking and approaches tend to be treated as peripheral rather than central (Denzin, Lincoln \& Tuhiwai-Smith, 2008). This, however, does a disservice to collaboration, ignoring the natural synergies that indigenous approaches have with the concept and the contribution they can make to enhance inter-cultural teaching and learning contexts. Kaupapa Māori, for example, is essentially a collaborative approach that "respects, provides for and supports all participants through whakawhanaungatanga (the building of relationships)" (Sexton, 2011, p. 37). Such an approach does not seek to exclude other cultures, but seeks to 
provide balance by challenging, questioning and critiquing dominant cultural hegemonies (Sexton, 2011).

Critical reflection is recognised as an important factor in developing collaborative teaching and learning and cross-cultural understanding. Despite recognising the challenges, members of interdisciplinary teaching teams have been known to benefit professionally from being exposed to other teaching styles and are accordingly able to become more creative in their own practice (Bryant et al., 2014). This is noted further as encouraging reflexivity in teaching practice (Lester \& Evans, 2009). Teachers engaging inter-culturally with colleagues and students can themselves experience transformative learning and professional development, enabled through in-depth reflection on their own ways of constructing knowledge (Vatalaro, Szente \& Levin, 2015). Collective reflection in teaching and learning practice is important because it can provide for holistic understanding through engaging multiple perspectives (Harvey, Coulson \& McMaugh, 2016).

\section{RESEARCH APPROACH}

The platform for this research was built through the intensive processes of collective critical reflexivity conducted through the first two years of the teaching team's collaboration. The research itself was established by three of the core members of the team in a three-day retreat in which collective reflection and discussion took place, and a framework for a critically reflexive model of research was agreed. The research intentions were agreed to align with a Participatory Action Research approach, which was considered suitable because the researchers were also the key participants, and it would allow the team members to be at the centre of, and driving, the research (Cousin, 2009). It also fitted well with the teaching team's established way of working with its incorporation of collaboration, collective reflection and iterative cycles of planning, action, observation and reflection (Harvey et al., 2016), which accordingly enabled collaborative knowledge production (Chatterton, Fuller \& Routledge, 2007).

The research process was grounded by ethical considerations to ensure that all members of the teaching team were given equal opportunity to participate in the research, freely share their experiences and reflections on the collaborative experience, and contribute as much as they chose to in terms of their ideas, without any pressure to take any particular view ${ }^{1}$ All teaching team members over the first two years of course delivery were invited to contribute reflections about their experiences of working in a multi-disciplinary team within an intensive collaborative teaching model, teaching concepts of culture and society to broadly multicultural cohorts of students, and implementing a range of new engagement and assessment practices. Ultimately, the four core members and two other team members participated in the collective reflections. ${ }^{2}$ The process was initiated by the four core staff separately recording their learning from the experiences, incorporating whatever was important to them about that experience. These were

\footnotetext{
${ }^{1}$ Ethical approval was received from AUT Ethics Committee in May, 2017.

2 Two additional team members agreed to participate but withdrew as they moved to new teaching contracts in other institutions.
} 
then shared with each other and common themes and ideas were identified. A focus group was subsequently held that included the two other team members. Guiding questions were based on the identified themes, and new ideas were invited, and then explored through discussion on how they reinforced, challenged, or shed new light on the originally identified themes.

The analysis was conducted thematically and iteratively, identifying terms used by participants that reflected similar meanings and ideas gained from their experiences, and also those that individuals held differently, or articulated in different ways. In this process the core team members adopted a cyclical system of sharing their analysis of the reflections, checking and discussing how the reflections were interpreted according to their different perspectives, and from their conceptual understandings gained from reading associated literature. The culmination of the analysis was a collective agreement by the group of the key principles which underpinned their understanding of what had worked in the collaboration, and which provided the basis of a framework interpretation of their approach. The main themes from the reflections follow.

\section{KEY THEMES FROM THE REFLECTIONS}

\section{Collaborative approach}

From the start of the course delivery, the teaching team deliberately worked together in a highly integrated and closely collaborative way. The uniqueness of the approach was important to all those who shared their reflections. Participants agreed that working closely with each other was crucial to achieving the course objectives, and for ensuring consistency, depth of learning and support for the vision they had for student achievement in the course. They gauged the success of their strategies on the quality of student engagement and the work that those students produced; some of which they experienced as quite exceptional.

The team's working approach was based on the core members' understandings of collective and distributed leadership. This understanding ensured shared responsibility and created an environment for all team members to have a voice in how the paper was run. This was articulated as there having been no sense of just one person saying "this is how we're going to do it". While the team leader took responsibility for coordination of the team, planning was not based on one specific way of doing, but by constantly questioning how to achieve the "most effective way" for the team. The emphasis in practice was to be integrative, but with flexibility for each member to be able to adapt ideas to suit their individual strengths and stay 'true' to their own disciplinary and cultural identity. The success of this strategy was highlighted by one team member's statement, "I liked how we worked on everyone's ideas, but you could still do your own thing in front of your tutorial group", and another's that, "you could use your own 'agency' and develop your own style".

Each individual's comfort with collaboration tended to relate to prior experience, personal preference and/or cultural affinity. Team members who had previously worked in secondary teaching school contexts or student mentoring programmes expressed that they had similarly shared with colleagues their curriculum and student engagement strategies. Having a cultural background that put value in collective responsibility was also especially important for Māori team 
members, one of whom noted that the team's working approach aligned with her own ontological position informed by indigenous cultural frameworks.

The team members reflected that this collaboration was different to what they had previously experienced in tertiary education settings, where they had either delivered courses on their own, or within a model of shared teaching where responsibilities and tasks were divided. This was not to say that they did not share ideas with colleagues, but had not done so before in such an explicitly integrative way. They also recognised that their model was not an approach that everyone would like, especially because it could seem to require concerted effort to communicate and share with each other. For some, it felt like it was a more time and labour-intensive way of working which required time to be designated for engaging in the team's communications, planning and attending the regular meetings, and ensuring that their individual work schedules could meet the team's preparation and delivery deadlines. Those needs could cause tensions with each member's other teaching and professional obligations. The pay-off, however, was that less time was required for individual teaching preparation because it was largely done together at the team meetings. Sharing ideas and being constantly 'on the same page' about the approach, they felt, also provided the team with a dynamic ability to implement change as was seen necessary, and be more culturally responsive in their teaching practices.

\section{Developing common understanding and purpose across disciplines}

Establishing common understanding and purpose within the team was crucial to building the collaboration across the diverse team membership. In the first phase of the course's development, common understanding was developed through the team's intensive consultative process and their trialling of the first assessments which identified how specific concepts related their personal worldviews. An early opportunity for building understanding of each other was an exercise that aligned with the dialogic Māori introduction of pepeha. ${ }^{3}$ Pepeha enabled each person to share their whakapapa ${ }^{4}$ and professional history, enabling the team to realise the diversity of the group's cultural backgrounds, and to understand how each members' culture, identity, disciplinary perspective and personal influences positioned their specific perspective within the teaching team. This enabled familiarity to grow between the individual team members about their respective ontological positioning and provided openings for discussion about disciplinary interpretations of concepts.

As the wider team membership changed from semester to semester due to the allocation of teaching roles from the various schools, it was important for the core team to ensure that common understanding was maintained. The core members pursued a number of strategies to initiate new members, and enable them to 'come up to speed' with the course objectives and team approach. The team leader met individually with new members before the semester start to explain the course and collaborative approach so they did not feel 'dropped in it'

\footnotetext{
${ }^{3}$ Pepeha or a formulaic expression is a structured narrative that provides a form of introduction for Māori that links people together through the inter-relationships with natural and ancestral places, narratives and knowledge.

${ }^{4}$ Whakapapa refers to family or genealogic lineage.
} 
when teaching commenced. Repeating the pepeha exercise was another way new members were introduced to the group to encourage familiarity. Ensuring that team planning discussions continually referenced the aims of the course was also important in keeping ideas about the course approaches aligned. Those who had been 'new' members expressed that while these strategies helped, they had at times felt less 'in tune' with the course approaches because they had not been involved in its early development. This created concerns that there should be more consistent team membership from semester to semester; however, it was equally acknowledged that changes in staff brought different, 'fresh' perspectives about the course content and delivery strategies, and had often injected new energy into the team.

The close collaborative approach engendered the feeling that the team had developed its own distinctive working culture. Trust in each other, and willingness to engage, became central elements to the team's culture. It was built through the regular conversations in team meetings, and deeper discussions and shared reflections that were part of three moderation meetings per semester. The regular sharing and reflections enabled the team members to deepen their sense of shared values and commitment to each other and the course, and to build understanding of each other's perspectives. With the growth of trust, it was possible for constructive and robust conversations, sometimes involving the negotiation of opposing views, to be conducted amicably. These conversations established common grounds for the team's practice, and enabled agreements that members' approaches might diverge but still align with the ultimate course goals.

\section{Roles of team members}

The commitment to collective leadership within the team manifested in shared senses of responsibility, where members recognised that they took on unique roles within the team. These emerged as they found their place in the team based on their own professional and disciplinary strengths. First and foremost, every team member identified that they felt one role was for them to be a 'voice' for their discipline in the course, and ensure that their disciplinary perspective was represented in relation to others', especially in how different concepts were being studied. This was an important aspect of the team's planning discussions and in each member's teaching approach in tutorial sessions. Additionally, two team members particularly expressed that they felt their responsibility was to ensure the alignment of the variety of content in the course from week to week to the course's learning objectives. One described this as ensuring the content remained "on course" and always relevant to the learning aims, while the other referred to ensuring the "dots were joined" for students between the diverse concepts and issues being explored in the course, and the 'fit' of different disciplinary perspectives with these.

Individuals also played roles in maintaining the collective functioning of the team. The course leader sought to be the "glue" for the team, providing support and encouragement for all team members, facilitating the content "behind the scenes", and ultimately taking responsibility for any "hard decisions" required in relation to student achievement and monitoring. She also noted that there was a need at times to put herself in the forefront of the team, especially so it was clear to students that final responsibility in decisions for the course was hers. A Māori staff member felt it important that her approach contributed manaakitanga to the 
team, ${ }^{5}$ which involved supporting collectivist responsibility while ensuring that all team members were valued and supported. She further sought to ensure that Māori were valued as tāngata whenua ${ }^{6}$ and that Māori knowledge elements were present through all of the course content and pedagogical approaches. Another who had previous experience with a dialogic, experiential pedagogical framework that aligned well with the course approach sought to support others who were new to it, and explain ways it could be applied in teaching practice.

A member new to teaching expressed that she had found her own way to contribute to the team over time. For her, the team support enabled her to observe, learn and feel a freedom to try new things in her teaching. The distinctive roles that arose within the team allowed collective, distributed leadership to play out, because different individuals at times would, according to their strengths, lead the team discussions or produce ideas that all members could incorporate in their teaching.

\section{Professional learning from the collaboration}

The team members saw themselves as being on the same journey, learning from each other, from their students, and about themselves as teaching professionals. They found that in order to provide support to students in this personalised learning, they would be required to share their own world views more than they felt they would in other course settings. It was therefore "nice not to feel alone" in teaching the paper, to feel supported, and to hear others' ideas that could keep them 'fresh' in their own teaching practice. The sense of shared responsibility and support was especially important given the incorporation of 'new' content, engagement, teaching strategies and assessment approaches.

The team journey could be challenging, however. The dialectical tensions between disciplines, maintaining conceptual and theoretical integrity, and constantly needing to think and solve problems across disciplines created a more complex teaching experience for team members. They found that they needed to constantly reflect on how the content and engagement with different disciplinary perspectives could meet what the students needed from this course. A priority was to use the students' work to inform the team's evaluation of their own teaching strategies and practices and future planning.

The continual sharing of different perspectives within the team helped members to come up with teaching strategies that would cater to the "more complex audience" of disciplinary and cultural mixes of students in tutorial groups. One suggested that they needed to be "light on [their] feet" in facilitating class discussions to deal with the complexity of views that were expressed, but having already encountered different perspectives in the team discussions helped her to be more confident, flexible and resilient in engaging with students in the classroom discussions. Where differences in views or interpretations arose in tutorials, these could be approached as providing opportunities for deeper, active learning. For example, one team member reflected that she was able to provide students with conceptual tools "to make sense of dissonances" that could become apparent in class.

\footnotetext{
${ }^{5}$ Manaakitanga: providing support, kindness, generosity and hospitality

${ }^{6}$ Tangata whenua: the people of the land
} 
Members gained professionally through learning from each other across disciplines and cultures. Subtleties in difference between disciplinary perspectives came to be better understood, for example one reflected that even when she thought she knew about other disciplines "theoretically and in an abstract way, when you see it in practice, you think oh wow we use this quite differently, or through this particular lens." Another commented from engaging with other disciplinary perspectives, she had learnt more about the wider study context that students in her BA programme experienced. One team member also felt that being in the team had made her "go back to school" to get up to date with current issues and how they were being analysed from different disciplinary areas. Some noted that this experience had helped to reinforce their own disciplinary identity, first by seeing where there were synergies and divergences with colleagues from other programmes, and further by feeling they had to "raise their game" in "being in a bigger gig" as part of a team.

The close, integrative collaborative approach was acknowledged as needing constant support and monitoring. This was not only for the team, but in providing 'role-modelling' for students in the course. Team members' abilities to collaborate could be complicated by the differences in the wider work contexts and responsibilities that they dealt with outside of this course. For the teaching team, external support was important if members were to provide "safe learning spaces" for the students, sustain their energy and enthusiasm towards collaboration, deliver the course, and deal with the complexity in teaching that was required. Thus, sound institutional support for the team required managers to be aware and supportive of the requirements of collaboration. Furthermore, administrative structures, processes and support for the course had to be robust and consistent across the faculty.

In all, the professional learning for team members was greatest where they felt the collaboration complemented and added value to their wider work contexts. One found the whole paper "fascinating", even with its complexities. Another found it suited her because "I liked exchanging ideas, and I liked being in the environment to do that; freedom and sharing of ideas." The ability for all to provide input was recognised as making the work less straightforward, but more rewarding for each member, as one commented that "if it's all straightforward then you have someone controlling things." The team members tended to all agree with one member's reflections in summing up their experience of collaboration:

....it reminded me how satisfying collaboration is; we don't have many opportunities to do true collaboration...I think of collaboration as slightly messy and muddly - I think that's when you know you're doing it right...It reminded me I have a good capacity for that, and it reminded me that I do enjoy it.

\section{DISCUSSION}

The Culture and Society course objectives and design sought to meet the demands of modern universities noted by scholars such as Brooks (2017), Millar (2016) and Moore (2011) in equipping students with abilities to critically think and reflect across disciplinary areas. Belief in these learning objectives was an 
important factor that bound the teaching team members to collaboration, as has understanding what has worked, why, and how this can inform their teaching practices in future.

A core goal of this research has been to identify the elements of success in collaboration that will be crucial in sustaining it and other similar endeavours in the long run. Five core groups of elements emerged that the team members agreed provided a necessary basis of their collaboration, and are illustrated in Figure 1. The framework shows that the components are not necessarily separate, but are mutually necessary and reinforcing.

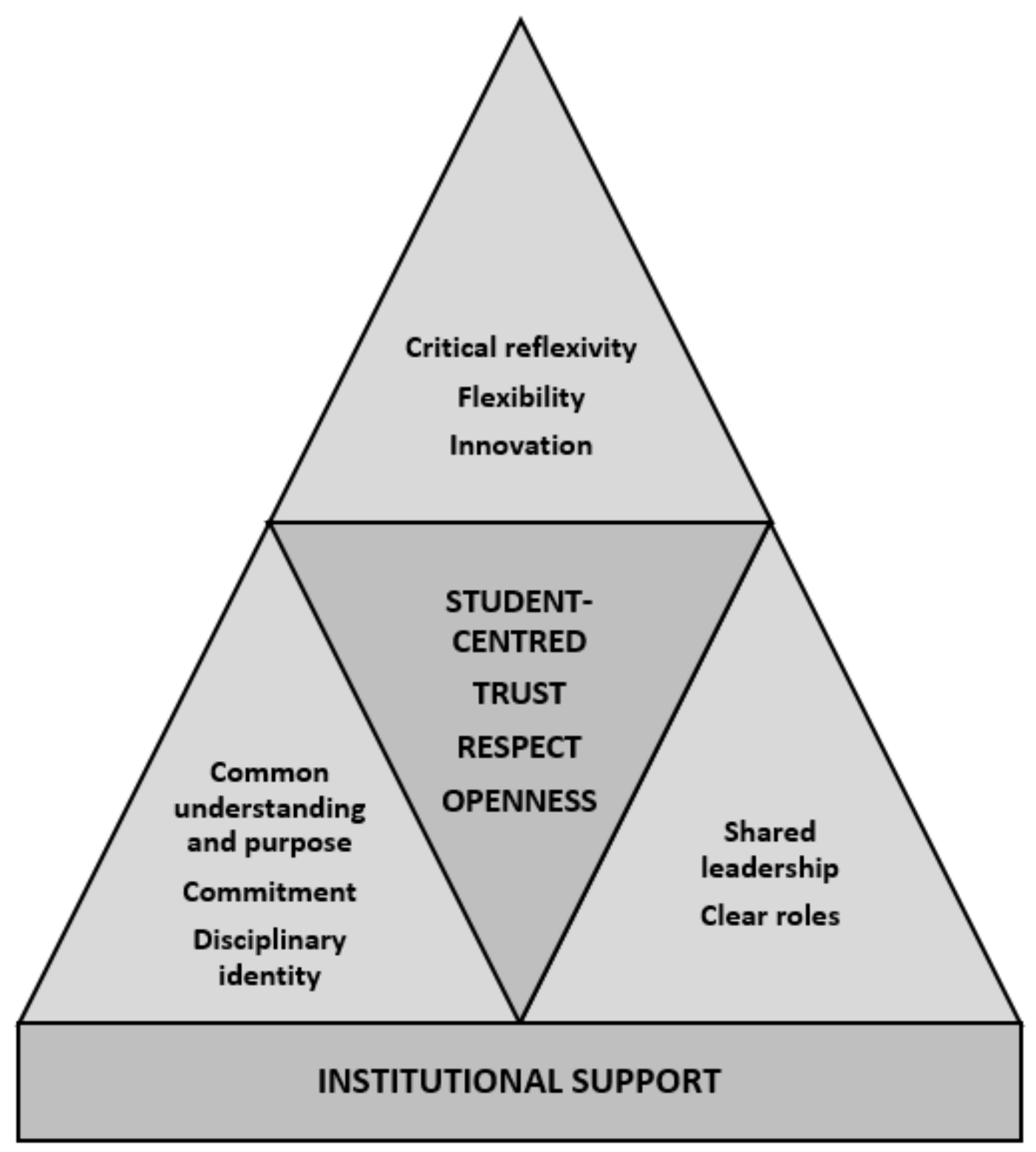

Fig. 1: A framework for collaboration

This collaborative approach was identified as quite different to teaching approaches that are "highly individualised" as is recognised as common in higher education teaching (Pharo et al., 2014, p. 342), or "sequenced solo teaching" that often is developed in team teaching (Lester \& Evans, 2009, p. 374). This team's 
approach matched what was termed by Bryant et al. (2014, p. 93) a "traditional" model of collaboration, which requires each team member to make a real commitment to integrate teaching practices, while also ensuring appropriateness to their own disciplinary understanding.

For each team member to make a real commitment to work in collaboration, common understanding and purpose is required from the start. These elements tend to be assumed rather than explicitly dealt with in literature on collaboration and communities of practice, but members of this team argued that this needed to be deliberately built. Willingness to engage in the process, and learn and understand the purpose, were central ingredients identified by the team members as a basis for this collaboration. In 'buying in' to the interdisciplinary course and the collaboration, however, team members needed to know and maintain their own sense of disciplinary identity. The team members' concerns to maintain individual disciplinary integrity within the course structures relate to findings by Millar (2016) and Conley (2015) that interdisciplinarity can create fears about the limit of depths of learning. While the team members expressed awareness of this, they simultaneously emphasised the benefits they had experienced, emphasising the strength of taking a holistic, interdisciplinary view of specific concepts rather than focusing on the tensions between the views. An important factor in the collaboration was to allow, in effect, for the 'internal [disciplinary] gaze' (Frodeman, 2014) to be maintained while also turning outward, thus helping members to reinforce their understandings of the similarities and differences between their and others' disciplines. This is something Frodeman (2014) argues is necessary to break through the limitations wrought by single disciplinary approaches. The experience also provided team members with greater appreciation of how their discipline fitted within the wider faculty suite of programmes, something that has been noted as often lacking in more individualised higher education contexts (Pharo et al., 2014).

Conducting collaboration required shared leadership and senses of responsibility to the team from all members. The sharing of responsibilities that arose in this study reflects understandings of successful distributed leadership (Jones, Lefoe, Harvey \& Ryland, 2012). The collective sharing of responsibility produced sound 'horizontal' links that could support the team structure (Jones et al., 2012; Raelin, 2011). Research into collaborative teaching experiences has said little of the roles allocated or taken on by individual team members, but this research highlighted the importance of clear role recognition and empowerment for each of the team members. Knowing what they each contributed in a disciplinary sense and from what they drew on as professionals from their personal, cultural backgrounds provided each with a real sense of ownership within the team.

The strength of the collaboration was in what the team could collectively achieve. Collective critical reflexivity was an extremely important ingredient in its dynamism and ability to innovate. Working closely together, reflecting regularly and critically considering how the students were responding to content enabled the team to make changes and adopt different teaching strategies quickly if necessary. This enabled flexibility and adaptability across the team, and at the same time served to reinforce the team culture. The team members found they had a sense similar to that expressed by Lester and Evans (2009), that collaborative team members could contribute to "building something bigger" ( $p$. 379), and create more innovation in their practice. At the same time the individual 
team members could develop as critically reflexive teaching practitioners, thereby experiencing transformative learning themselves (Mezirow, 1997). Individual benefit served to reinforce the collaborative effort, supporting views that collective reflection can enable the growth of shared values and purpose, thereby providing the basis for a vibrant community of practice (Taylor, Mellor \& McCarter, 2016).

Central to all of these elements were the crucial values of studentcentredness, openness, trust and respect that wove into and reinforced each of the other elements of the collaboration. The team members' commitments to the course's goals and their reflective practice were inherently student-centred, and were maintained as such throughout the course delivery and reflections on their work. Team members all emphasised the necessity that their engagement and commitment to cooperating with each other was based on trust; trust in each other, and trust in the process (Pharo et al., 2014). Relational trust, with the aspects of interpersonal respect, personal regard for others, role competence and personal integrity (Day, 2011) reflects well the ideas put forward by team members about the basis of their collaboration. It enabled reciprocity to be not just a core element of the team's work (Lester \& Evans, 2009), but a deliberate way of acting. Reciprocity can be seen in the team members' concerns to look out for and support each other in their work, to inspire each other to continue to engage in the process (Newell, 2010 cited in Bryant et al., 2014), and to ensure appropriate induction of new team members, to ensure the sustainability of the course and to deliver the best for their students.

Overall, the soundness of the collaboration lay in support from the wider institution. The reality for each team member was that contributing to this course was just one of many roles each played within their academic practice, and other demands often needed to be juggled alongside their commitment to the collaboration. The time-intensive nature of collaboration reflected similar challenges to other collaborative teaching research findings (Lester \& Evans, 2009). The need that team members expressed for appropriate institutional support aligns with Bryant et al. (2014) who highlight the influence of institutional structures on the ease of interdisciplinary collaboration. Figure 1 illustrates the necessity of this last crucial component, showing institutional support as providing a firm foundation for any similar collaboration to have any real chance of success.

\section{CONCLUSION}

Just as Colwill and Boyd (2008) emphasise that transformative learning does not take place in a 'conflict-free' classroom, nor does the professional teaching development of multi-disciplinary teaching teams. This research highlighted that the reality of team teaching is that it is not just about having a collective will to work together, but that it requires hard work to establish and maintain a sound team culture. Team members must actively work at, and take responsibility for, their part in the collaboration through a shared sense of purpose, understanding and commitment to the work. To do so they each need to clearly understand, and be invested in, the team's vision for the course. They also need to be ready and willing to deal with challenges that arise; and challenges do. It is however, by trusting the process and the team, and by working hard to embody the team spirit in their practice, that team members can deal with 
challenges, and the magic of transformational learning and professional development can take place for the individuals and for the team.

To maintain the integrity of such a collaboration in the long term, especially in the face of personnel and institutional changes, both the teaching team and the wider institution need to be prepared to maintain and nurture the elements of success that have been identified. Within the teaching team, there needs to be established processes that can build on the successes of the past and ensure there is 'room' to build new innovations into teaching practices. These need to be supported by an institutional framework that is sound and flexible in grounding and supporting the collaboration, while also providing the freedom and encouragement for new teaching ideas and innovations to emerge.

Manuscript Submitted: August 6, 2017

Revised Manuscript Received: November 20, 2017

Revised Manuscript Accepted: November 23, 2017 


\section{REFERENCES}

Beijaard, D., Meijer, P.C. and Verloop, N. (2004). Reconsidering research on teachers' professional identity. Teaching and Teacher Education, 20, 107128. https://doi.org/10.1016/j.tate.2003.07.001

Brooks, C.F. (2017). Disciplinary convergence and interdisciplinary curricula for students in an information society. Innovations in Education and Teaching International, 54(3),

206-213. https://doi.org/10.1080/14703297.2016.1155470

Bryant, L.H., Niewolny, K., Clark, S. \& Watson, C.E. (2014). Complicated spaces: Negotiating collaborative teaching and interdisciplinarity in higher education. The Journal of Effective Teaching, 14(2), 83-101.

Chatterton, P., Fuller, D. \& Routledge, P. (2007). Relating action to activism: Theoretical and methodological reflections. In S. Kindon, R. Pain, \& M. Kesby, (Eds.), Participatory action research approaches and methods: Connecting people, participation and place (pp.216-222). New York, NY: Routledge.

Colwill, E. \& Boyd, R. (2008). Teaching without a mask? Collaborative teaching as feminist practice. NWSA Journal, 20(2), 216-246.

Conley, D.T. (2015). Breadth vs. depth: the deeper learning dilemma [Webblog post]. Education Week, Retrieved 18 Nov 2017 from: http://blogs.edweek.org/edweek/learning_deeply/2015/10/breadth_vs_de pth the deeper learning dilemma.html

Cousin, G. (2009). Researching learning in higher education: An introduction to contemporary methods and approaches. New York, NY: Routledge.

Day, C. (2011). The layering of leadership. In J. Robertson, \& H. Timperley (Eds.) Leadership and learning (pp.13-26). London, United Kingdom: Sage Publishing.

Duke Corporation Education (2005). Building effective teams. Chicago, IL: Dearborn Trade Publishing.

Denzin, N.K., Lincoln, Y.S \& Tuhiwai-Smith, L. (2008). Handbook of critical and indigenous methodologies. London, United Kingdom: Sage Publications Inc.

Frodeman, R. (2014). The end of disciplinarity. In P. Weingart \& B. Padberg (Eds.), University experiments in interdisciplinarity: Obstacles and opportunities (pp.175-198). Bielefeld, Germany: Transcript.

Harland, T. \& Pickering, N. (2011). Values in higher education teaching. Oxon, United Kingdom: Routledge.

Harvey, M., Coulson, D. \& McMaugh, A. (2016). Towards a theory of the ecology of reflection: Reflective practice for experiential teaching in higher education. Journal of University Teaching and Learning Practice, 13(2), 120.

Jones, S., Lefoe, G., Harvey, M. \& Ryland, K. (2012). Distributed leadership: a collaborative framework for academics, executives and professionals in higher education. Journal of Higher Education Policy and Management, 34(1), 67-78. https://doi.org/10.1080/1360080X.2012.642334

Lester, J.N. \& Evans, K.R. (2009). Instructors' experiences of collaborative teaching: building something bigger. International Journal of Teaching and Learning in Higher Education, 20(3), 373-382. 
Mezirow, J. (1997). Transformative learning: theory to practice. New Directions for Adult and Continuing Education, 74, 5-12. https://doi.org/10.1002/ace.7401

Meyer J.H.F. \& Land R. (2003). Threshold concepts and troublesome knowledge: linkages to ways of thinking and practising. In C. Rust (Ed.), Improving student learning. Theory and Practice - Ten years On (pp.412-424). Oxford, United Kingdom: OCSLD.

Millar, V. (2016). Interdisciplinary curriculum reform in the changing university. Teaching in Higher Education, 21(4), 471-483. https://doi.org/10.1080/13562517.2016.1155549

Moore, T.J. (2011). Critical thinking and disciplinary thinking: a continuing debate. Higher Education Research and Development, 30(3), 261-274. https://doi.org/10.1080/07294360.2010.501328

Pedersen, K.W. (2017). Supporting collaborative and continuing professional development in education for sustainability through a communities of practice approach. International Journal of Sustainability in Higher Education, 18(5), 681-696. https://doi.org/10.1108/IJSHE-02-2016-0033

Peiser, G. \& Jones, M. (2014). The influence of teachers' interests, personalities and life experiences in intercultural languages teaching. Teachers and Teaching, 20(3), 375-390. https://doi.org/10.1080/13540602.2013.848525

Pharo, E., Davison, A. McGregor, H., Warr, K. \& Brown, P. (2014). Using communities of practice to enhance interdisciplinary teaching: lessons from four Australian institutions. Higher Education Research and Development, $33(2)$,

341-354. https://doi.org/10/1080/07294360.2013.832168

Raelin, J.A. (2011). Work-based learning: how it changes in leadership. Development and Learning in Organizations: An International Journal, 25(5), 17-20. https://doi.org/10.1108/14777281111159393

Sexton, S.S. (2011). Putting Māori in the mainstream: Reflections of a culturally relevant pedagogy. Australian Journal of Teacher Education, 36(12), 3345. https://doi.org/10.14221/ajte.2011v36n12.2

Smith, H.A. \& McKeen, J.D. (2003). Creating and facilitating communities of practice. In C.W. Holsapple (Ed.). Handbook on Knowledge Management, Vol.1. New York, NY: Springer, pp.393-407.

Summerlee, A.J.S. (2016). The wheel is spinning but the hamster is dead. HERDSA News, Spring 2016, 3-4. Retrieved from: http://www.herdsa.org.au/sites/default/files/HERDSANews20163803.pdf

Taylor, G., Mellor, L. \& McCarter, R. (2016). Work-related learning and the social sciences. Oxon, United Kingdom: Routledge.

Walker, M. (2005). Higher education pedagogies: A capabilities approach. London, United Kingdom: Society for Research into Higher Education.

Wallerstein, I. (2003). Anthropology, sociology and other dubious disciplines. Current Anthropology, 44(4), 453-465.

Vatalaro, A., Szente, J. \& Levin, J. (2015). Transformative learning of pre-service teachers during study abroad in Reggio Emilia, Italy: a case study. Journal of the Scholarship of Teaching and Learning, 15(2), 42-55. https://doi.org/10.14434/josotl.v15i2.12911 


\section{ABOUT THE AUTHOR(S)}

\section{CAROL NEILL}

School of Social Sciences and Public Policy

Auckland University of Technology

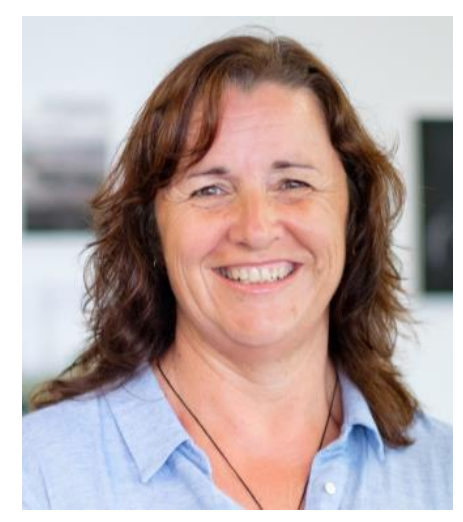

Carol Neill is a lecturer in the School of Social Sciences and Public Policy at AUT and programme leader of the BA Social Sciences. Carol's academic background is in History, and her teaching work has aimed to develop a strong interest in student engagement in the Social Sciences, and how interdisciplinary education enhances broader educational goals for both career and citizenship advancement.

\section{DEBORAH CORDER}

School of Language and Culture

Auckland University of Technology

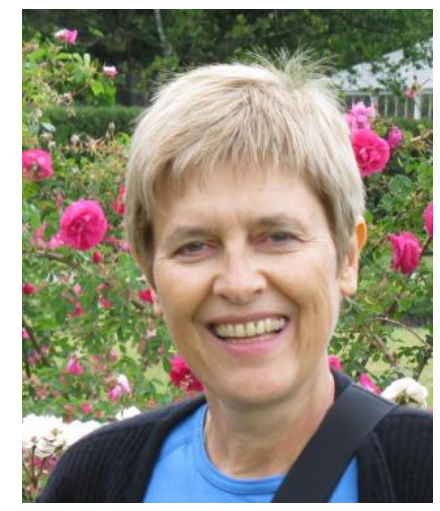

Deborah (Debbie) Corder is Associate Head of School in the School of Language and Culture at AUT. She has taught Japanese at secondary and tertiary levels, and now teaches on courses in intercultural competence and East Asian values and beliefs, which she developed with colleagues. Deborah is programme leader of the BA International Studies, which has a strong focus on cultural intelligence and global issues. Her research interests are intercultural competence, study abroad, learner autonomy and ICT, including multi-user virtual environments. 
KERI-ANNE WIKITERA

School of Hospitality and Tourism

Auckland University of Technology

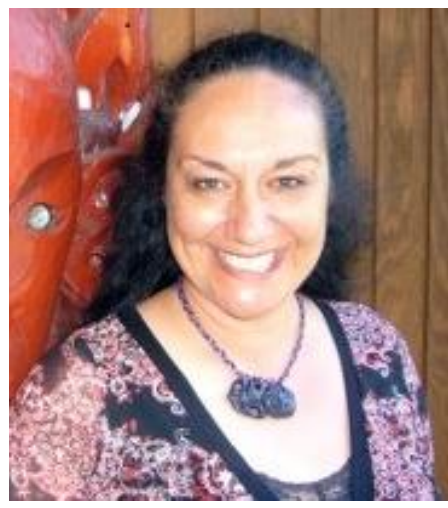

Keri-Anne Wikitera is a lecturer in Tourism in the School of Hospitality and Tourism at AUT. Keri's hapū Ngāti Wahiao and Tūhourangi are recognised as two of the nation's first Māori tourism entrepreneurs and this background has been an important driver of her academic career. Keri is passionate about supporting students to understand their own cultural identity and how it influences and shapes their own educational and professional experiences.

\section{STEPHEN COX}

School of Hospitality and Tourism

Auckland University of Technology

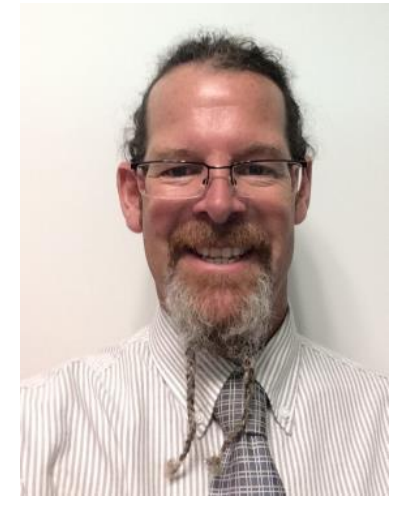

Stephen Cox is a lecturer in the School of Hospitality and Tourism at AUT University. He holds undergraduate degrees in Hospitality and Teaching along with a Master's degree in Education. Stephen's passion for engagement in student learning has been reflected at faculty and university level with awards for excellence in teaching and learning. $\mathrm{He}$ is committed to team teaching and collaborative approaches to the enhancement of the student experience.

The opinions expressed are those of the paper author(s) and not the New Zealand Journal of Teachers' Work. Copyright is held by individual authors but offprints in the published format only may be distributed freely by individuals provided that the source is fully acknowledged. [ISSN-1176-6662] 